\title{
Design of LED power supply with high power factor based on SEPIC converter
}

\author{
Gao Tian ${ }^{1}$, Wang $\mathbf{Q i}^{2}$, Yang Yan ${ }^{1 \mathrm{a})}$, and Hou Jing ${ }^{1}$ \\ ${ }^{1}$ School of Electronic and Information, Northwestern Polytechnical University, \\ Xi'an, China \\ ${ }^{2}$ School of Electronic Information Engineering, Xi'an Technological University, \\ Xi'an, China
}

a)gtonline@sina.com.cn

\begin{abstract}
A single ended primary inductor converter (SEPIC) converter based light emitting diode (LED) power supply, which can achieve power factor correction (PFC) and constant-current driver for the LED in the critical conduction mode, is presented in this paper. The circuit principle is described in detail. Meanwhile the formulas for metal-oxide semiconductor field-effect transistor (MOSFET) switch-on time, switching frequency and the main influences of power factor are given. Experimental results show that the power can drive the LED with high efficiency in virtue of its high power factor, low power loss and stable output. Furthermore, it can be applied to low power lighting occasions with the simple structure and the high reliability.
\end{abstract}

Keywords: LED, PFC, SEPIC converter, critical conduction mode

Classification: Electron devices, circuits, and systems

\section{References}

[1] C.-L. Shen, Y.-E. Wu and C.-T. Tsai: 2011 6th IEEE Conference on Industrial Electronics and Applications (2011) 2384. DOI:10.1109/ICIEA.2011. 5975992

[2] N. P. Papanikolaou, E. J. Rikos and E. C. Tatakis: IEE Proc. Electric Power Applications 148 (2001) 177. DOI:10.1049/ip-epa:20010262

[3] Y. Zhongming, F. Greenfeld and Z. Liang: 34th Annual Conference of the IEEE Industrial Electronics Society (2008) 1961. DOI:10.1109/IECON.2008. 4758257

[4] L.-M. Wu, T.-X. Huang and K.-S. Kuan: Power Electronics and Motion Control Conference (IPEMC) (2012) 215. DOI:10.1109/IPEMC.2012.6258905

[5] M. Ali, M. Orabi, M. E. Ahmed and A. E. Aroudi: Electric Power and Energy Conversion Systems (2011) 1. DOI:10.1109/EPECS.2011.6126799

[6] H. J. Chiu, Y. K. Lo, J. T. Chen, S. J. Cheng, C. Y. Lin and S. C. Mou: IEEE Trans. Ind. Electron. 57 (2010) 735. DOI:10.1109/TIE.2009.2027251

[7] M. Ali, M. Orabi, M. E. Ahmed and A. El-Aroudi: Power and Energy (PECon) (2010) 501. DOI:10.1109/PECON.2010.5697634

[8] Z. Ye, F. Greenfeld and Z. Liang: Applied Power Electronics Conference and Exposition (2009) 546. DOI:10.1109/APEC.2009.4802711

[9] Z. Ye, F. Greenfeld and Z. Liang: Power Electronics Specialists Conference (2008) 2657. DOI:10.1109/PESC.2008.4592343 
[10] V. Eng, U. Pinsopon and C. Bunlaksananusorn: Electrical Engineering/ Electronics, Computer, Telecommunications and Information Technology 1 (2009) 136. DOI:10.1109/ECTICON.2009.5136982

\section{Introduction}

With the advancement of new materials and manufacture process, a new lighting source, that is, high brightness LED is now attracting more and more attentions from both academy and industry. LED has high luminous efficiency, long lifetime and no poison mercury content compared with the conventional fluorescent lamp, therefore, LED lighting is called "green lighting".

Many converter topologies can be used to drive the LED string, such as boost, buck-boost, SEPIC, flyback, half bridge converter and forward converter. The boost converter is simple and highly efficient, and is suitable for large LED string applications where the input voltage is comparatively low and the isolation is not mandatory. The boost structure attains better power factor correction feature but its output voltage is higher than ac-side voltage and power components withstand high voltage stresses. The Buck-Boost converter can obtain an output voltage magnitude either larger or smaller than the input. Nevertheless, there is a polarity reversal on the output and an isolation driver for active switch is required [1]. The flyback converter is the most commonly used topology for low power offline applications, especially when the isolation is necessary. However, the flyback transformer only runs in one quadrant. The magnetic core is not fully utilized [2]. The SEPIC converter can be designed for wide range of output and input ratios, it also allows to regulate output voltages that are greater than or less than the input voltage applied to the power converter itself (like buck-boost converters). The input of the converter is similar to the boost circuit with a smaller input current ripple to reduce the input of electromagnetic interference (EMI), and its output is similar to the flyback circuit to easily realize the isolation. Compared with various topologies, the SEPIC converter with great adaptability to output voltage and high power factor has become one of the best LED power supply topologies $[3,4,5,6]$.

The SEPIC converter can operate in continuous conduction mode (CCM), discontinuous conduction mode (DCM) and critical conduction mode (CRM). The CCM and DCM operation modes for LED lamp applications have been discussed in several papers $[7,8,9]$. In this paper, we focus on the study of CRM operation mode. In the CRM operation mode, the output rectifier diode of the SEPIC converter works under the Zero Current Switching (ZCS), thus improving the conversion efficiency of the converter. Meanwhile, the power factor correction can be achieved easily due to the linear relationship between the average input current and the input voltage. A large input filter used for eliminating the current harmonics in the DCM converter is unnecessary. 
This paper proposes a single-stage single LED power supply circuit. It adopts a SEPIC converter which operates in CRM mode. The proposed circuit is compact and minimizes the circuit components. The advantages of using SEPIC converter in the proposed circuit topology will be discussed in this paper. The operating principles of the proposed circuit will also be given in details. The feasibility and performance of the proposed circuit will be verified through a laboratory prototype.

\section{Principle of SEPIC converter}

The concise structure of the SEPIC converter is shown in Fig. 1. The capacitor $\mathrm{C}_{1}$ and the inductor $\mathrm{L}_{2}$ are added to the Boost converter. The capacitor $\mathrm{C}_{1}$ insulates the input and the output, and provides protection for the short circuit load. $\mathrm{i}_{\mathrm{L} 1}, \mathrm{i}_{\mathrm{L} 2}$ are the currents on the inductor $\mathrm{L}_{1}, \mathrm{~L}_{2}$, respectively, and $i_{D}$ is the current of the diode $\mathrm{D}$.

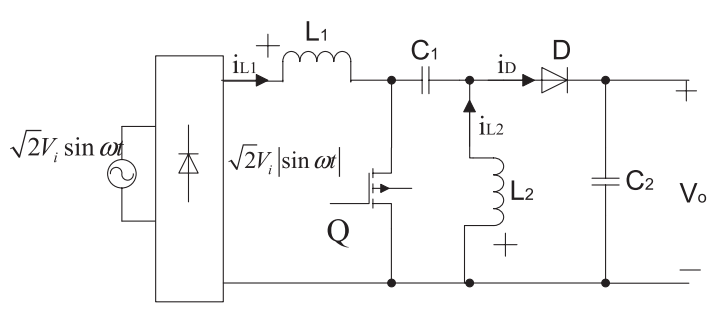

Fig. 1. SEPIC converter topology

According to the switching state of the switch Q in the working stage, the SEPIC converter is divided into two operating modes (switch on and switch off) for analysis. Assume the switching period of the switching tube is Ts, the conduction time is $\mathrm{T}_{\mathrm{ON}}$, the turn-off time is $\mathrm{T}_{\mathrm{OFF}}$, and $\mathrm{D}$ is the duty ratio of the switch Q.

(1) Mode 1. When the switch Q is turned off, two loops are formed in the circuit.

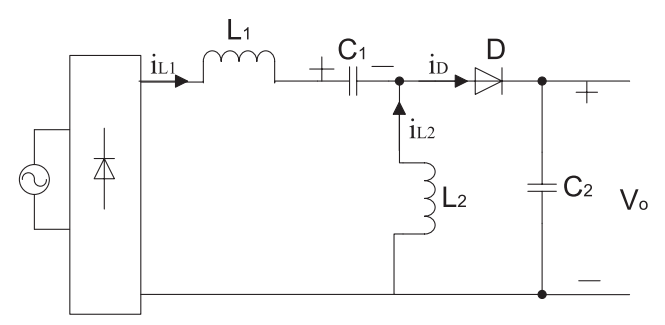

Fig. 2. Equivalent circuit when switch is off

As shown in the Fig. 2, the first loop is composed of a power supply, $\mathrm{L}_{1}$, $\mathrm{C}_{1}$, D and the load. While $\mathrm{Q}$ is off, the inductor $\mathrm{L}_{1}$ discharges, the inductive current $i_{\text {L1 }}$ decreases, the capacitor $\mathrm{C}_{1}$ stores energy and provides an output for the load. Assuming that the diodes are ideal and the conduction voltage drop is zero, the voltage across the inductor $\mathrm{L}_{1}$ is: 


$$
V_{L 1}=V_{i}-V_{C 1}-V_{O}
$$

The second loop consists of the inductor $\mathrm{L}_{2}$, the output capacitor $\mathrm{C}_{2}$ and the load. The energy storage of the inductor $\mathrm{L}_{2}$ is released to the load through the diode $\mathrm{D}$, while the inductive current $\mathrm{iL}_{2}$ is decreased. The voltage across the inductor $\mathrm{L}_{2}$ is equal to the negative value of the output voltage:

$$
V_{L 2}=-V_{O}
$$

In the turn-off stage of the switch $\mathrm{Q}$, the current through the diode $\mathrm{D}$ is $i_{D}=i_{L 1}+i_{L 2}$.

By volt-ampere relationship of the inductor, the followings can be obtained:

$$
\begin{array}{ll}
i_{L 1}(t)=i_{L 1}(0)+\frac{V_{i}}{L_{1}} \cdot T_{O N}-\frac{V_{C 1}+V_{o}-V_{i}}{L_{1}} \cdot t & T_{O N}<t \leq T_{S} \\
i_{L 2}(t)=i_{L 2}(0)+\frac{V_{C 1}}{L_{2}} \cdot T_{O N}-\frac{V_{o}}{L_{2}} \cdot t & T_{O N}<t \leq T_{S}
\end{array}
$$

(2) Mode 2. When the switch Q is turned on, three loops are formed in the circuit.

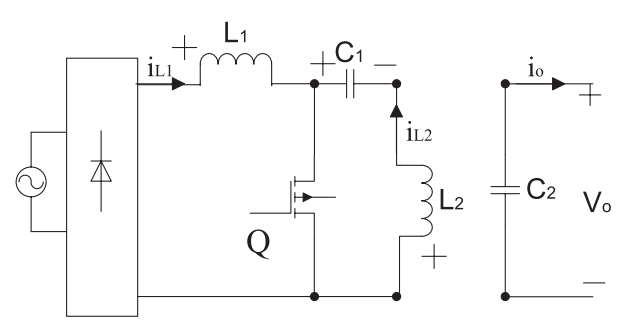

Fig. 3. Equivalent circuit when switch is on

As shown in the Fig. 3, the first loop is composed of the inductor $L_{1}$ and the switch $\mathrm{Q}$. The input current across the inductor $\mathrm{L}_{1}$ and the $\mathrm{Q}$ is stored in the inductor $\mathrm{L}_{1}$, thus the inductive current $\mathrm{i}_{\mathrm{L} 1}$ increases linearly.

The second loop includes the capacitor $\mathrm{C}_{1}$, the inductor $\mathrm{L}_{2}$ and the switch Q. When the capacitor $\mathrm{C}_{1}$ discharges through $\mathrm{L}_{2}$ and the switch $\mathrm{Q}$, the current through the $\mathrm{Q}$ is:

$$
i_{Q}=i_{L 1}+i_{L 2}
$$

The third loop comprises the output capacitor $\mathrm{C}_{2}$ and the load. The capacitor $\mathrm{C}_{2}$ supplies power to the load.

The voltage of the inductor $L_{1}$ is equal to the input voltage $V_{i}$ and the voltage of the inductor $\mathrm{L}_{2}$ is equal to the voltage of the capacitor $\mathrm{C}_{1}\left(\mathrm{~V}_{\mathrm{C} 1}\right)$. That is,

$$
\begin{aligned}
& V_{L 1}=V_{i} \\
& V_{L 2}=V_{C 1}
\end{aligned}
$$

Then, we can obtain: 


$$
\begin{array}{ll}
i_{L 1}(t)=i_{L 1}(0)+\frac{V_{i}}{L_{1}} \cdot t & 0<t \leq T_{O N} \\
i_{L 2}(t)=i_{L 2}(0)+\frac{V_{C 1}}{L_{2}} \cdot t & 0<t \leq T_{O N}
\end{array}
$$

In the CRM operation mode, $i_{L 1}(0)=-i_{L 2}(0)$, while the switch $\mathrm{Q}$ is turned on. The current through the switch $\mathrm{Q}$ is:

$$
i_{Q}(t)=i_{L 1(t)}+i_{L 2(t)}=\left(\frac{v_{i}}{L_{1}}+\frac{v_{c 1}}{L_{2}}\right) t
$$

When $t=T_{O N}, i_{L 1}$ and $i_{L 2}$ reaches the maximum value.

Based on the volt-second balance of the inductors L1 and L2, we can get:

$$
\begin{aligned}
& \frac{V_{i}}{L_{1}} \cdot T_{O N}=\frac{V_{C 1}+V_{o}-V_{i}}{L_{1}} \cdot T_{O F F} \\
& \frac{V_{C 1}}{L_{2}} \cdot T_{O N}=\frac{V_{O}}{L_{2}} \cdot T_{O F F}
\end{aligned}
$$

Combining the above two equations, we can get:

$$
\frac{V_{i}}{V_{o}}=\frac{T_{O F F}}{T_{O N}}=\frac{1-D}{D}
$$

Eq. (13) shows that the SEPIC converter can regulate output voltages greater or less than the input voltage. Therefore, the working voltage range of the circuit is wide.

\section{PFC analysis of SEPIC converter}

As shown in Fig. 1, the input voltage is a sinusoidal wave through the fullwave rectifier.

$$
V_{i}\left(2 \pi f_{L} t\right)=\sqrt{2} \cdot V_{i} \cdot\left|\sin \left(2 \pi f_{L} t\right)\right|
$$

Where $V_{i}$ is the effective value of the line voltage and $f_{L}$ is the frequency of the line voltage.

Since the switching frequency is far greater than the bus frequency, the bus voltage in a switch period can be assumed to be constant. The output of the compensation loop can be considered constant in a half power frequency cycle because the bandwidth of the control loop is lower than the frequency of the line voltage. Therefore, the envelope of the switch Q is sinusoidal [10], and the peak current is proportional to the line voltage, expressed as:

$$
i_{Q p k}(t)=i_{Q p k} \cdot\left|\sin \left(2 \cdot \pi \cdot f_{L} \cdot t\right)\right|
$$

When the switch is turned on, the peak current of the switch $Q$ is:

$$
\begin{aligned}
& i_{Q p k}(t)=\left(\frac{1}{L_{1}}+\frac{1}{L_{2}}\right) \cdot V_{i}\left(2 \pi f_{L} t\right) \cdot T_{O N} \\
& T_{O N}=\frac{i_{Q p k}}{\sqrt{2} \cdot V_{i} \cdot\left(\frac{1}{L_{1}}+\frac{1}{L_{2}}\right)}
\end{aligned}
$$

As shown in Eq. (17), when the SEPIC circuit works in the CRM operation mode, the switch-on time of the switch $\mathrm{Q}$ is fixed under the condition of a certain input voltage and load. So we can get: 


$$
T_{O F F}=\frac{\sqrt{2} \cdot V_{i} \cdot\left|\sin \left(2 \pi f_{L} t\right)\right|}{V_{o}} \cdot T_{O N}
$$

From Eq. (18), we can see that the switch-off time relates to the time $t$ and changes with the input voltage. Then the switching frequency changes with the input voltage of the SEPIC circuit.

According to the charge balance principle for the capacitor $\mathrm{C}_{1}$ in a switching period, we can get:

$$
\left(i_{L 1}(0)+\frac{1}{2} \cdot \frac{V_{i}\left(2 \pi f_{L} t\right)}{L_{1}} \cdot T_{O N}\right) \cdot T_{O F F}=\left(i_{L 2}(0)+\frac{1}{2} \cdot \frac{V_{i}\left(2 \pi f_{L} t\right)}{L_{2}} \cdot T_{O N}\right) \cdot T_{O N}
$$

Substituting $i_{L 1}(0)+i_{L 2}(0)=0$ into Eq. (19), we can get:

$$
i_{L 1}(0)=\frac{V_{i}\left(2 \pi f_{L} t\right) \cdot T_{O N}}{2\left(T_{O N}+T_{O F F}\right)}\left(\frac{T_{O N}}{L_{2}}-\frac{T_{O F F}}{L_{1}}\right)
$$

Then the average current of the inductor $L_{1}$, i.e., the input current of the circuit, is given as follows:

$$
i_{\text {L1avg }}\left(2 \pi f_{L} t\right)=\frac{1}{2} \cdot \frac{V_{i}\left(2 \pi f_{L} t\right)}{L_{1}} \cdot T_{O N}+i_{L 1}(0)=\frac{1}{2} \cdot i_{Q p k} \cdot \frac{\left|\sin \left(2 \pi f_{L} t\right)\right|}{1+K \cdot\left|\sin \left(2 \pi f_{L} t\right)\right|}
$$

Where, $K=\frac{\sqrt{2} V_{i}}{V_{o}}$ is the ratio of the input peak voltage to the output voltage. It can be seen that the smaller $\mathrm{K}$ is, the closer to the ideal sinusoidal wave the input voltage is, and the higher the power factor is.

\section{Experimental circuit}

A LED driving power topology diagram based on SEPIC converter is shown in Fig. 4. The circuit operates in the CRM operation mode. In the figure, the control chip is L6562, the main components parameters are as follows: the inductances of $\mathrm{L}_{1}$ and $\mathrm{L}_{2}$ are $1.9 \mathrm{mH}$ and $1.0 \mathrm{mH}$, respectively; the capacitance

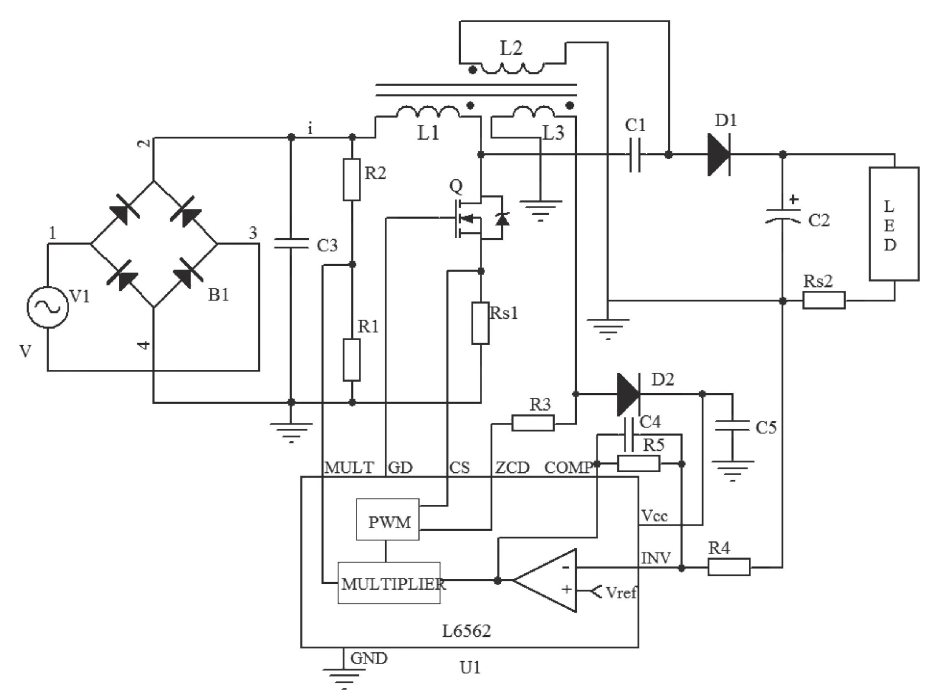

Fig. 4. LED power driver based on SEPIC converter 
of $\mathrm{C}_{1}$ and $\mathrm{C}_{2}$ are $0.47 \mu \mathrm{F}$ and $220 \mu \mathrm{F}$, respectively, and the switch $\mathrm{Q}$ is 07N60C3. The main technical indexes of the driving power are as follows: input voltage: $176 \sim 264 \mathrm{VAC}$; output voltage: $200 \mathrm{~V}$; output current: $350 \mathrm{~mA}$; output power: $70 \mathrm{~W}$; power factor: $\geq 92 \%$ and efficiency: $\geq 90 \%$.

\section{Experimental results analysis}

Fig. 5 shows the input current waveform and input voltage waveform when the output is $70 \mathrm{~W}$. It can be seen that the input current follows the input voltage. Besides, we can see that the input current curve is close to the standard sinusoidal wave and the measured power factor is greater than 0.96. Fig. 6 presents the relationship curve between the input voltage and the power factor. It is clear that the power factor decreases as the input voltage increases. This is consistent with the conclusions from Eq. (21). When the output voltage is constant, the lower the input voltage is and the smaller the ratio of the input voltage to the output voltage is, and the higher the power factor is.

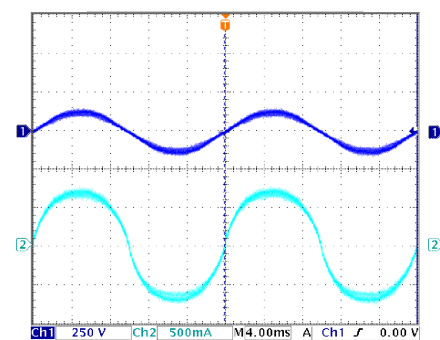

(a)

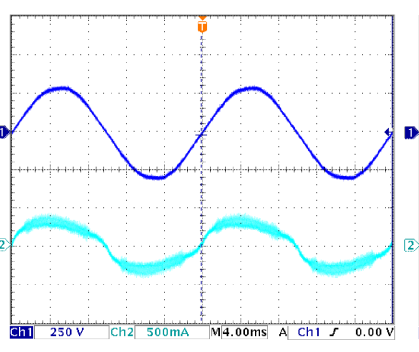

(b)

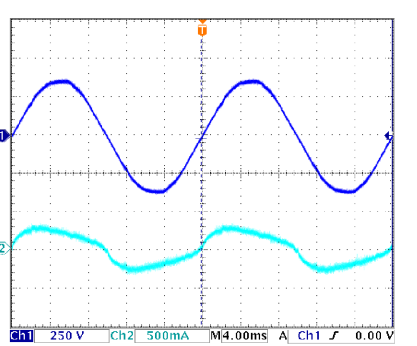

(c)

Fig. 5. Input current $(2 \mathrm{~A} / \mathrm{div}, 4 \mathrm{~ms} / \mathrm{div})$ and input voltage $(250 \mathrm{~V} / \mathrm{div}, 4 \mathrm{~ms} / \mathrm{div})$

(a) Input current waveform with $90 \mathrm{~V}$ input voltage

(b) Input current waveform with $220 \mathrm{~V}$ input voltage

(c) Input current waveform with $270 \mathrm{~V}$ input voltage

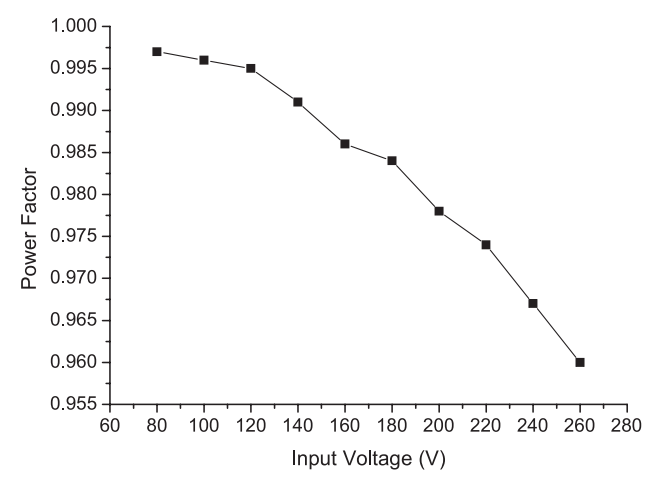

Fig. 6. Relationship curve between input voltage and power factor 
Fig. 7 shows the typical drain-source voltage and gate signal of the switch Q. The envelope of the drain-source voltage follows the rectified ac voltage. More detailed drain-source voltage is shown in Fig. 7(b). The relationship curve between the input voltage and the efficiency is given in Fig. 8. Clearly, when the input voltage is between $90 \mathrm{~V}$ and $270 \mathrm{~V}$, the overall efficiency is more than $90 \%$, at full load.

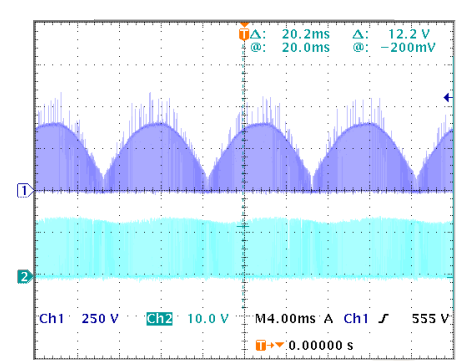

(a)

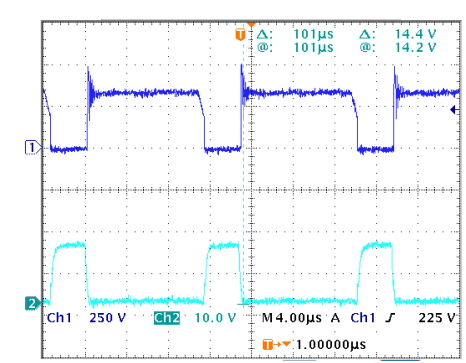

(b)

Fig. 7. Drain-source voltage and gate voltage of the switch $Q$ (a) Drain-source voltage: $250 \mathrm{~V} /$ div; gate voltage: $10 \mathrm{~V} /$ div; time: $4 \mathrm{~ms} /$ div

(b) Drain-source voltage: $250 \mathrm{~V} /$ div; gate voltage: $10 \mathrm{~V} /$ div; time: 4 us/div

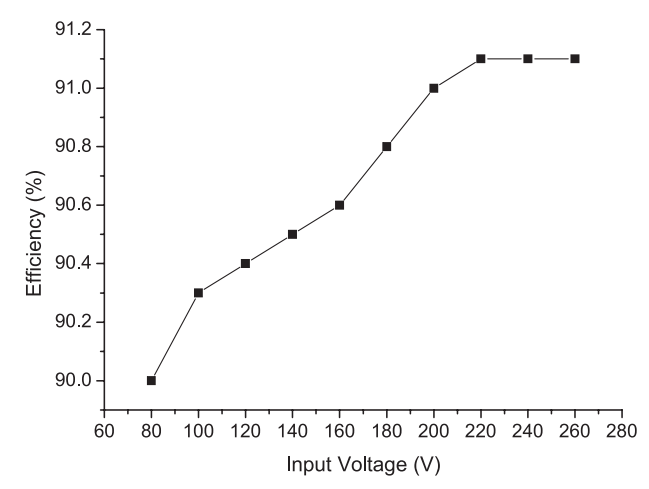

Fig. 8. Relationship curve between input voltage and efficiency

\section{Conclusion}

A high power factor SEPIC converter for LED lighting application with universal input voltage has been studied in this paper. It is particularly suitable for LED power supply since it is single-stage and can step up/down. Especially, the stability of the SEPIC topology operating in critical conduction mode was analyzed in detail. Based on these analyses, a LED driving power with SEPIC structure was designed, and the laboratory prototype was built and tested. The experimental results showed that the LED driving power based on SEPIC structure can achieve power factor correction and constant current control of the LED with few devices and low losses. Besides, high performances such as a power factor greater than 0.96 and an overall 
efficiency more than $90 \%$ were verified, which make the proposed design have great practical values both in performance and cost.

\section{Acknowledgments}

This research was supported by the Shaanxi Industrial Research Project Funding (No. 2013K07-13) and Natural Science Basic Research Plan in Shaanxi Province of China (No. 2013JM8006). 